\title{
Gastric Perforation in a 28-Month-Old Child: Complicated by Peritonitis Admitted to the Surgical Emergency Room after a Case
}

\author{
Abdoulaye Touré ${ }^{*}$, Fofana Naby², Amadou Yalla Camara ${ }^{3}$, Joseph Donamou ${ }^{3}$, \\ Boubacar Atigou Dramé1, Oularé Ibrahima², Camara M'mah Lamine ${ }^{3}$, Bangoura Almamy1, \\ Camara Mariama Mohamed1, Emile Camara², Godwe Justin Naibe1
}

${ }^{1}$ Anesthesia-Intensive Care Unit at the National Ignace Deen Hospital, Conakry, Guinea

${ }^{2}$ General Surgery Department of the National Ignace Deen Hospital, Conakry, Guinea

${ }^{3}$ Anesthesia-Intensive Care Unit at the Donka National Hospital, Conakry, Guinea

Email: *atfmamad@gmail.com

How to cite this paper: Touré, A., Naby, F., Camara, A.Y., Donamou, J., Dramé, B.A., Ibrahima, O., Lamine, C.M., Almamy, B., Mohamed, C.M., Camara, E. and Naibe, G.J. (2020) Gastric Perforation in a 28-Month-Old Child: Complicated by Peritonitis Admitted to the Surgical Emergency Room after a Case. Open Journal of Emergency Medicine, 8, 118-124.

https://doi.org/10.4236/ojem.2020.84013

Received: October 29, 2020

Accepted: December 25, 2020

Published: December 28, 2020

Copyright $\odot 2020$ by author(s) and Scientific Research Publishing Inc. This work is licensed under the Creative Commons Attribution International License (CC BY 4.0).

http://creativecommons.org/licenses/by/4.0/

\begin{abstract}
We report the case of a 28-month-old male child with no particular history who was admitted to the emergency room for severe abdominal pain associated with vomiting, asthenia and fever at $39.1^{\circ} \mathrm{C}$ that had progressed for 4 days. He was conscious, polypneic at 32 cycles/min on admission. On palpation the abdomen was distended, painful as a whole, more pronounced in the epigastrium. There was abdominal contracture, generalized defense, a cry with sudden decompression of the umbilicus. On abdominal auscultation, there was a disappearance of prehepatic dullness, a decrease in the dullness of the flanks and absence of hydro-aeric noises. On the digital rectal examination, Douglas's cul de sac was bulging and sensitive. An unprepared X-ray of the abdomen revealed diffuse grayness, lateral gas crescent pneumoperitoneum under diaphragm. The preoperative resuscitation consisted of the placement of a nasogastric tube, a urinary catheter, a peripheral venous route and the fluid electrolyte rebalancing adapted according to the blood ionogram, early antibiotic therapy with broad aero and anaerobic spectrum. Surgical management under general anesthesia found at laparotomy a perforation of the anterior surface of the duodenal bulb which we estimate to be 1 $\mathrm{cm}$ in diameter with fibrin deposits. The gesture was the toilet of the peritoneal cavity; suture of the bank and the operative consequences were simple.
\end{abstract}

\section{Keywords}

Resuscitation, Gastric Perforation, Child, Peritonitis, Ignace Deen 


\section{Introduction}

Spontaneous gastric perforation is a serious and rare condition in children, especially beyond the neonatal period [1]. It is a rare life-threatening entity in newborns, potentially difficult for treating physicians. The reported incidence is 1/5000 live births and spontaneous gastric perforation accounts for $7 \%$ of all gastrointestinal perforations in newborns [2]. Factors associated with spontaneous gastric perforation include prematurity, asphyxia, birth defects, stress at birth, vigorous respiratory resuscitation measures, increased intragastric pressure caused by distal obstruction, and anatomical abnormalities of the stomach [3] [4]. The mechanisms of occurrence are still poorly understood and remain a subject of controversy [5]. We present here the case of a gastric perforation in a 28 months old child complicated by acute generalized peritonitis.

\section{Case Presentation}

The 28-month-old male child, with no particular history, was admitted to the emergency room for severe abdominal pain associated with vomiting, asthenia and fever that had progressed for 4 days. These symptoms had previously led the parents to consult two private facilities where the child was said to have received a treatment that the parents could not remember. On admission the child was conscious, febrile at $39.1^{\circ} \mathrm{C}$, blood pressure $100 / 60 \mathrm{~mm} \mathrm{Hg}$, heart rate 136 beats per minute, respiratory rate 32 cycles/min, oxygen saturation at $96 \%$ in ambient air and a blood sugar level of $1.06 \mathrm{~g} / \mathrm{L}$. The physical examination showed a child with an altered general condition, polypneic with a distended abdomen, painful in the epigastrium, tender as a whole with abdominal contracture and generalized defense, a cry at the sudden decompression of the umbilicus, disappearance of pre-hepatic dullness, sloping dullness of the flanks and absence of hydro-aeric noises on auscultation. On the digital rectal examination, Douglas's cul de sac was bulging and sensitive. The remainder of the physical examination noted moderate dehydration. Management in the emergency department consisted of taking a venous route, placing a nasogastric tube which brings back $180 \mathrm{ml}$ of greenish liquids and urinary catheter which brings back $200 \mathrm{ml}$ of concentrated urine, hydration by Ringer Lactate, analgesia (paracetamol).

The emergency X-ray of the abdomen without preparation (PSA) showed diffuse grayness secondary to fluid effusion, pneumoperitoneum in a lateral gas crescent under diaphragm (Figure 1). Biologically, there is a normochromic, normocytic anemia with a hemoglobin level at $6 \mathrm{~g} / \mathrm{dl}$, a hematocrit of $27 \%$, the platelet at $150 \mathrm{G} / \mathrm{L}$, hyperleukocytosis at $18,000 / \mathrm{mm}^{3}$, hyponatremia at $=130$ $\mathrm{mmol} / \mathrm{l}$, hypochloremia at $90 \mathrm{mmol} / \mathrm{L}$ and hypokalaemia at $3.3 \mathrm{mmol} / \mathrm{L}$.

The diagnosis of acute peritonitis generalized by perforation of a hollow organ was made. Resuscitation consisted of adequate fluid and electrolyte rebalancing according to the blood ionogram, early broad-spectrum parenteral antibiotics based on metronidazole $250 \mathrm{mg} / 8 \mathrm{~h}$, and ceftriaxone $500 \mathrm{mg} / 12 \mathrm{~h}$. An indication for surgery was raised in this emergency context. It was performed under general 
anesthesia. Rapid sequence induction with administration of rocuronium and Sellick maneuver was performed. The hypnotic used was propofol. Intraoperatively analgesia was provided by fentanyl as an opioid and maintenance by halothane as a halogen. Mechanical ventilation with an anesthesia ventilator was performed. The surgery lasted $60 \mathrm{~min}$. At laparotomy, we discovered $600 \mathrm{ml}$ of purulent fluids in the peritoneal cavity, a sample of this fluid was taken for bacteriological examination and exploration had revealed a perforation of the anterior face of the duodenal bulb which we estimate at $1 \mathrm{~cm}$. in diameter with fibrin deposits (Figure 2). A cleansing of the peritoneal cavity was rigorous, excision suture of the perforation control of hemostasis, wall closure and placement of a drain in the peritoneal cavity; Pad. Extubation was done on an operating table 30 minutes later and the patient was transferred to intensive care. The postoperative follow-up was simple, with resumption of transit on D4 and removal of the drains. The results of bacteriological sampling of fluid from the peritoneal cavity revealed polymicrobial flora sensitive to ceftriaxone on the antibiogram. On D6 the child had been transferred for general surgery and the dressing on D7. The child was allowed to be discharged on D10 with home monitoring. Complete file ablation was done on D14 with good healing of the operative wound (Figure 3 ).

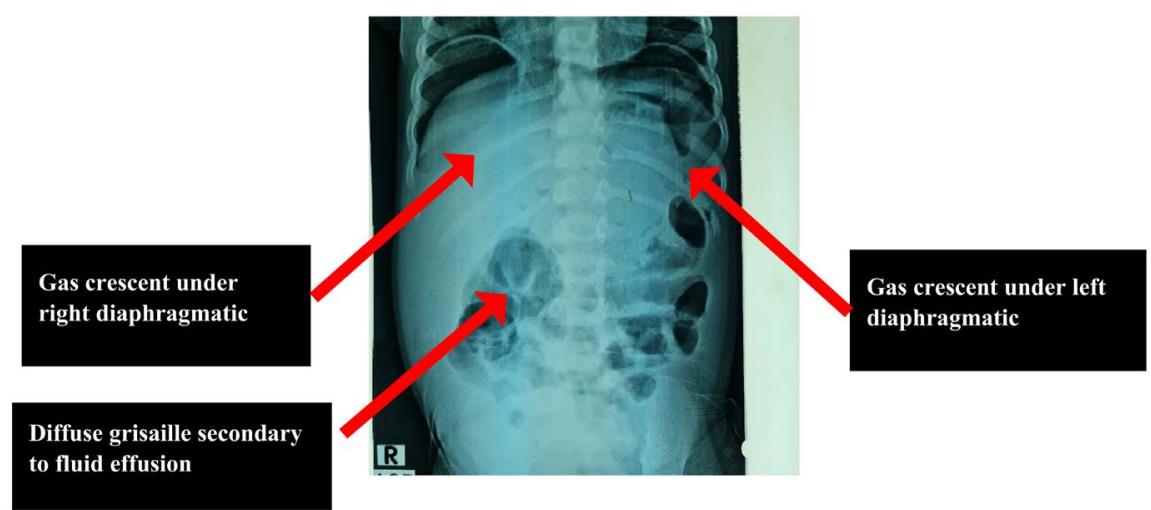

Figure 1. Pneumoperitoneum on an X-ray of the abdomen without preparation for a standing face.

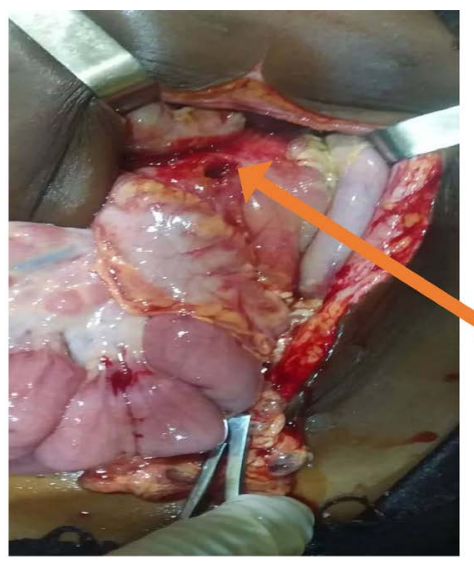

Perforation of the anterior

surface of the duodenal

bulb

Figure 2. Gastric perforation of the anterior surface of the duodenal bulb. 


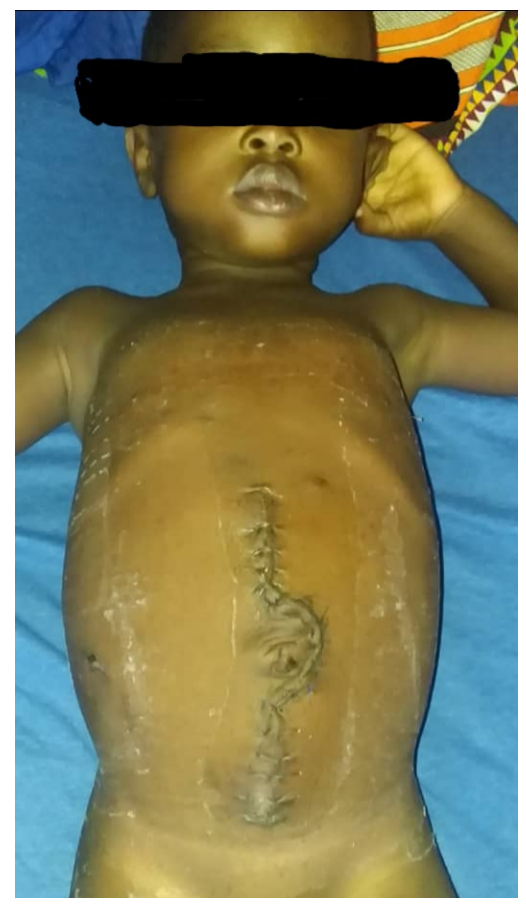

Figure 3. Operative wound on D14 after removal of the files.

\section{Discussion}

Spontaneous gastric perforation is a rare condition in children, more observed in newborns than in children beyond the neonatal period [1]. In the latter, gastric perforation is often secondary and may follow trauma, the use of a gastrotoxic drug, gastritis or gastric ulceration [2]. Reports of gastric perforations in preschool children are rare. Moreover, most of the documented cases have been attributed to a causal event [6], e.g. trauma [5], peptic ulceration or drug administration [7]. In contrast, several cases of spontaneous gastric perforation in preschool children have recently been reported in Japan [8] [9]. A study by Fukata et al. reported that the causative factor of this disease in preschool children is similar to that of newborns because her patient had a muscle defect under the microscope, but no muscle abnormalities were detected in any of the other patients [10].

In children, gastric perforation is a rare complication of peptic ulcer disease compared to adults [11] [12]. In addition, its inaugural character here is extremely rare and its preferred site in children is located at the level of the duodenum [12] [13]. For the surgeon, the major challenge will always remain to determine the etiology of peritoneal syndrome because the surgical approach depends on it.

In children, other etiologies of gastric perforation have been reported in association with Rett syndrome and Burkitt lymphoma. Children with Rett syndrome often have swallowing abnormalities, gastric atony, and/or decreased gastric motility that may rarely contribute to gastric dilation and thinning of the stomach wall, which can compromise gastric blood flow and increase the risk of 
perforation [14]. Potential mediators of spontaneous gastric perforation in Burkitt's lymphoma are tumor necrosis, myeloid toxicity, immunosuppression and protein malnutrition [15]. In our case, we have not found any convincing causes.

If cases with obvious predisposing anatomical factors (such as obstruction of gastric outflow) or traumatic events are excluded, the etiology of NGP is still controversial, but prematurity, low birth weight (LBW), severe infections and hypoxia are considered to be contributing factors [16] [17]. As a result, in 2008, Lin and colleagues reported 15 cases and reviewed the literature, finding a higher incidence of NGP in LBW infants (52\%) in particular, in extremely LBW infants, and suggested that premature infants are more likely to develop spontaneous gastric perforation due to the immaturity of gastric tissue [18]. Likewise, in the survey by Sato et al. [19], 11 of 42 newborns with gastric perforation were ELWB.

The perforation is often rounded in shape and localized on the posterior wall or the greater curvature of the stomach. In the present case, the clinical and radiological characteristics, as well as the location of the perforation in the stomach were generally identical to those often described in the literature [1].

On the X-ray of the abdomen without preparation, certain signs should also suggest a gastric perforation, it is a massive pneumoperitoneum, the absence of the hydroaeric level in the stomach and a weak intestinal pneumatization [20].

Gastric perforation is a serious condition, the prognosis of which has been improved in children thanks to advances in neonatal and pediatric resuscitation [1] [21] [22]. In our case, the diarrhea associated with feverish vomiting sometimes leads the diagnosis to that of gastroenteritis. The hypothesis of a perforation should always remain in the mind of the clinician in the emergency room. If in doubt, perform an abdominal ultrasound, failing which an X-ray of the abdomen without preparation to detect pneumonia accompanying primary peritonitis.

The limits of our observation are the rarity of gastritis perforations in children, few studies on the subject and most of the studies are old or with a small cohort.

\section{Conclusion}

In the emergency room or in private, any doctor must know how to evoke a surgical abdomen in front of a clinical picture of diffuse abdominal pain associated with diarrhea, vomiting or not with abnormal sensitivity in the child, perform an abdomino-pelvic ultrasound in the absence of an X-ray of the abdomen without preparation that may point to a perforation of a hollow organ. Intraoperative resuscitation lasting a few hours is the rule in most cases and early surgery improves the prognosis.

\section{Authors' Contributions}

All authors have read and approved the final version of the manuscript. 


\section{NB}

Free and informed consent has been requested from the child's parents for the surgery and the scientific publication of the case as well as the use of the images.

\section{Conflicts of Interest}

The authors declare no conflicts of interest regarding the publication of this paper.

\section{References}

[1] Libeer, F., Vanhamel, N., Huyghe, M. and Verlinden, E. (2007) Spontaneous Gastric Rupture in Non-Neonatal Children: A Case Report. Acta Chirurgica Belgica, 107, 560-563. https://doi.org/10.1080/00015458.2007.11680124

[2] Aydin, M., Deveci, U., Taskin, E., Bakal, U. and Kilic, M. (2015) Percutaneous Peritoneal Drainage in an Isolated Neonatal Gastric Perforation. World Journal of Gas troenterology, 21, 12987-12988. http://dx.doi.org/10.3748/wjg.v21.i45.12987

[3] Holgersen, L.O. (1981) The Etiology of Spontaneous Gastric Perforation in the Newborn: A Reassessment. Journal of Pediatric Surgery, 16, 608-613. https://doi.org/10.1016/0022-3468(81)90014-2

[4] Tan, C.E., Kiely, E.M., Agrawal, M., Brereton, R.J. and Spitz, L. (1989) Neonatal Gastrointestinal Perforation. Journal of Pediatric Surgery, 24, 888-892. https://doi.org/10.1016/S0022-3468(89)80589-5

[5] Semel, L. and Frittelli, G. (1981) Gastric Rupture from Blunt Abdominal Trauma. New York State Journal of Medicine, 81, 938-939.

[6] Paret, G., Yahav, J., Cohen, O., Nass, D.S. and Barzilay, Z. (1990) Chickenpox and Perforation of the Stomach. Journal of Pediatric Gastroenterology and Nutrition, 10, 121-125. https://doi.org/10.1097/00005176-199001000-00024

[7] Knight, K.M. and Doucet, H.J. (1987) Gastric Rupture and Death Caused by Syrup of Ipecac. Southern Medical Journal, 80, 786-787. https://doi.org/10.1097/00007611-198706000-00031

[8] Fukata, R., Tokiwa, K., Nakamura, K., Yanagihara, J., Iwai, N. and Hosoi, S. (1993) Idiopathic Gastric Rupture in a 19 Month Old Girl (in Japanese with English Summary). Journal of the Japanese Society of Pediatric Surgeons, 25, 343-346.

[9] Shigeta, H., Kuroda, O., Kawamoto, T., Hotta, T., Suzuki, H., Goto, M., Kajimura, M., Kawagoe, K. and Hurumoto, M. (1981) Idiopathic Gastric Perforation in a 2-Year-Old Woman (in Japanese with English Summary). Journal of the Japanese Society of Pediatric Surgeons, 13, 1533-1537.

[10] Mitani, K., Shimoji, H., Kondou, K., Matsushita, K., Koizumi, M., Yamashita, K. and Kobayashi, S. (1992) Idiopathic Gastric Rupture in Childhood (in Japanese). Gastroenterological Surgery, 15, 1535-1538.

[11] Bott, L., Vara, D., Missotte, I. and Ménager, C. (2003) Perforation of a Child's Gastric Ulcer: A Rare Complication, Based on One Case. Archives de Pédiatrie, 10 , 31-33. https://doi.org/10.1016/S0929-693X(03)00218-5

[12] Huang, S.C., Sheu, B.S., Lee, S.C., Yang, H.-B. and Yang, Y.-J. (2010) Etiology and Treatment of Childhood Peptic Ulcer Disease in Taiwan: A Single Center 9 Year Experience. Journal of the Formosan Medical Association, 109, 75-81. https://doi.org/10.1016/S0929-6646(10)60024-1

[13] Ndour, O., Bansouda, J., Fall, A.F., Alumeti, D.M., Diouf, C., Ngom, G., et al. (2012) 
Peritonitis from Peptic Ulcer Perforation in Children: About 4 Observations. Archives de Pédiatrie, 19, 1065-1069. https://doi.org/10.1016/j.arcped.2012.07.009

[14] Motil, K.J., Schultz, R.J., Browning, K., Trautwein, L. and Glaze, D.G. (1999) Oropharyngeal Dysfunction and Gastroesophageal Dysmotility Are Present in Girls and Women with Rett Syndrome. Journal of Pediatric Gastroenterology \& Nutrition, 29, 31-37. https://doi.org/10.1097/00005176-199907000-00010

[15] Guven, A., Demirbag, S., Atabek, C. and Ozturk, H. (2007) Spontaneous Gastric Perforation in a Child with Burkitt Lymphoma. Journal of Pediatric Hematology/Oncology, 29, 862-864. https://doi.org/10.1097/MPH.0b013e31815815e2

[16] Terui, K., Iwai, J., Yamada, S., Takenouchi, A., Nakata, M., Komatsu, S., et al. (2012) Etiology of Neonatal Gastric Perforation: A Review of 20 Years of Experience. Pediatric Surgery International, 28, 9-14. https://doi.org/10.1007/s00383-011-3003-4

[17] Duran, R., Inan, M., Vatansever, U., Aladağ, N. and Acunaş, B. (2007) Etiology of Neonatal Gastric Perforations: Review of 10 Years' Experience. Pediatrics International, 49, 626-630. https://doi.org/10.1111/j.1442-200X.2007.02427.x

[18] Lin, C.M., Lee, H.C., Kao, H.A., Hung, H.Y., Hsu, C.H., Yeung, C.Y., et al. (2008) Neonatal Gastric Perforation: Report of 15 Cases and Review of the Literature. Pediatrics \& Neonatology, 49, 65-70. https://doi.org/10.1016/S1875-9572(08)60015-7

[19] Sato, M., Hamada, Y., Kohno, M., Ise, K., Uchida, K., Ogata, H., et al. (2017) Neonatal Gastrointestinal Perforation in Japan: A National Survey. Pediatric Surgery International, 33, 33-41. https://doi.org/10.1007/s00383-016-3985-Z

[20] Schinasi, D.A. and Ellison, A.M. (2010) Spontaneous Gastric Perforation in a Child with Heterotaxy Syndrome. Pediatric Emergency Care, 26, 925-927. https://doi.org/10.1097/PEC.0b013e3181fe9175

[21] Qin, H., Yao, H. and Zhang, J. (2000) Gastric Rupture Caused by Acute Gastric Distension in Non-Neonatal Children: Clinical Analysis of 3 Cases. Chinese Medical Journal, 113, 1147-1149.

[22] Iacusso, C., Boscarelli, A., Fusaro, F., Bagolan, P. and Morini, F. (2018) Pathogenetic and Prognostic Factors for Neonatal Gastric Perforation: Personal Experience and Systematic Review of the Literature. Frontiers in Pediatrics, 6, 61. https://doi.org/10.3389/fped.2018.00061 